\section{Base Ratios in DNA in Male and Female Pseudococcus citri}

THe mealy bug, $P$. citri, affords a unique opportunity for analysis of biochemical changes underlying chromosome behaviour. In the male embryos, the entire paternal set, that is, one half the total number of chromosomes, remains condensed in the non-dividing nuclei; this facultative behaviour is similar to that of typical heterochrom. atic elements such as sex chromosomes ${ }^{1,2}$. Experiments with tritiated thymidine show that, like heterochromatic elements in other organisms ${ }^{3,4}$, the paternal set in the males reproduces asynchronously from the maternal, or euchromatic, set ${ }^{5}$. As measured by dominant lethality ${ }^{2}$ and mutant genes, the paternal set is genetically inert in the males, but some 'residual' influences can be demonstrated ${ }^{7,8}$.

Except for a few tissues, the paternal set maintains its heterochromaticity throughout the life of the male; at spermatogenesis it is segregated from the maternal, or euchromatic, set, and is not included in the sperm. In certain related forms, however, the heterochromatic state is reversed during spermatogenesis and the paternal chromosomes are segregated, apparently at random, to the sperm, to be transmitted to offspring of both sexes ${ }^{2}$. It seems likely, therefore, that the chromosomal changes responsible for facultative heterochromatization are ones which block rather than alter or destroy the genetic information. As a beginning we have isolated DNA from male and female insects and determined the base ratios from melting temperature and buoyant density measurements.

Mealy bugs were grown on potatoes, Solanum tuberosum L.; the large, gravid females containing both male and female embryos provided abundant material for establishment of experimental procedures; the second instar, prior to the extreme sexual dimorphism of later states, was used for the comparisons of males and females. No attempt was made to separate a yeast-like symbiont, present to about the same extent in males and females of the second instar; the DNA isolated includes symbiont nucleic acid also. DNA was isolated from $1 \mathrm{~g}$ of mealy bugs by the method of Marmur10. Phosphate was determined by the method of Fiske and SubbaRow ${ }^{11}$, scaled down for the analysis of $10 \mu \mathrm{g}$ of DNA. The best preparation of DNA had an $E(P)$ of 7,240. Chromatographic analysis was done on $1 \mathrm{mg}$ of DNA from gravid females, hydrolysed $2 \mathrm{~h}$ in 70 per cent formic acid at $175^{\circ} \mathrm{C}$. No methylcytosine was detected by Wyatt's procedure ${ }^{12}$. The average results from six analyses for base content are given in Table 1.

Table 1. Base CoNthint of DNA frox Gravid, Female Mealy Bugs

\begin{tabular}{ll}
\multicolumn{1}{c}{ Base } & Mole (\%) \\
Adenine & $\mathbf{3 4 \cdot 2} \pm 0.7$ \\
Thymine & $31.9 \pm 1.2$ \\
Guanine & $\mathbf{1 6 . 2} \pm 0.7$ \\
Cytosine & $17.8 \pm 1.3$ \\
Mole $(\%)$ guanine-cytosine & $\mathbf{3 4 . 0} \pm 1.1$
\end{tabular}

Table 2, Melting ThMPeratures of DNA from Meaty Bugs

\begin{tabular}{lll} 
Source & $\mathrm{Tm}$ & \multicolumn{3}{c}{ Mole (\%) guanine-cytosine } \\
Gravid females & $84.4 \pm 0.35$ & $37 \cdot 5 \pm 1 \cdot 0$ \\
Second instar males & $84.9 \pm 0.20$ & $38.7 \pm 0.6$ \\
Second instar females & $84.9 \pm 0.28$ & $38.7 \pm 0.8$
\end{tabular}

Melting temperature profiles were determined on a $D U$ Beckman spectrophotometer with a heated cell compartment. The solvent used was $0.15 \mathrm{M}$ sodium chloride$0.015 \mathrm{M}$ sodium citrate. The melting temperatures of DNA from gravid females and male and female second instar mealy bugs are given in Table 2. The mole per cent guanine-cytosine is calculated from published results ${ }^{18}$.

One melting profile for DNA of second instar males is given in Fig. 1. The profile of DNA from females is superimposable, but with a hyperchromicity of I.39. No heterogeneity due to symbiont or heterochromatin appears in these curves.

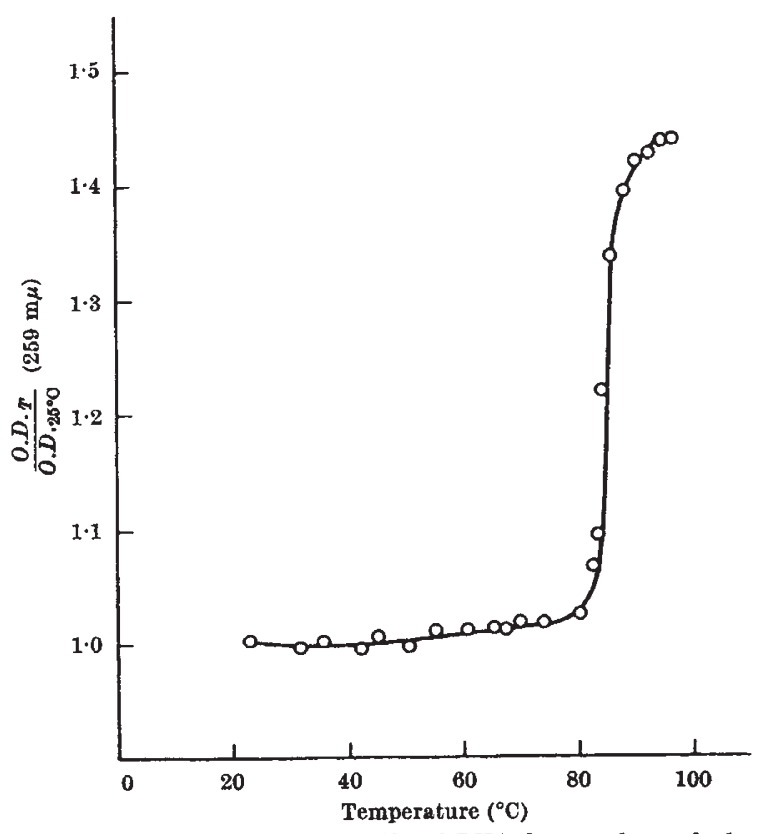

Fig. 1. Melting temperature profile of DNA from male mealy bug. (Optical densities uncorrected for volume expansion)

The buoyant densities of DNA from both male and female second instar insects was $1.695 \pm 0.001$, corresponding to $35 \cdot 8 \pm 1 \cdot 0$ mole (per cent) guanine-cytosine ${ }^{1 *}$.

The difference in base ratios by these three methods is not outside the variation reported in the literature ${ }^{14}$. It may be concluded that there is no evidence of a difference in base ratios greater than 1 per cent between DNA from male and female mealy bugs. Although genetic information no doubt could be destroyed without producing grossly detectable changes in base ratios, the fact that such cannot be demonstrated here is certainly in conformity with, rather than opposed to, the independent conclusion, from reversals of facultative heterochromatization, that the genetic information is masked rather than disrupted. Work is in progress to determine what differences may be found in other chromosomal components.

Buoyant densities in $\mathrm{Cs}^{14} \mathrm{Cl}$ were determined by $\mathrm{Dr}$. John Hearst, of the Department of Chemistry, University of California, at Berkeley. The $\lambda$ phage DNA used as a density standard was a gift of Dr. Monica Reilly, of the Department of Microbiology, University of California, at Davis.

This investigation was supported in part by a research grant (GB413-Brown) from the U.S. National Science Foundation and (G-4236-McLaren) from the National Institutes of Health, U.S. Public Health Service.

Mary W. LoewUS SPENCER W. Brown

Department of Genetics,

A. D. Mclaren

Department of Soils and Plant Nutrition,

University of California, Berkeley.

1 Hughes-Schrader, Sally, Adv. Genetics, 2, 127 (1948).

'Brown, S. W., and Nelson-Rees, W., Genetics, 46, 983 (1961).

3 Limia-de Faria, A., J. Biophy8. Biochem. Cytol., 6, 457 (1959).

- Taylor, J. H., J. Biophys. Biochem. Cytol., 7, 455 (1960).

- Baer, Adela S., Ph.D. thesis (Univ. Col., Berkeley, 1963).

- Weigmann, L., and Brown, S. W. (unpublished results).

'Nelson-Rees, W., Genetic8, 47, 661 (1962).

8 Nur, U., and Chandra, H. S., Amer. Nat., 87, 197 (1963).

- Brown, S. W., Chromosoma, 14, 360 (1963).

${ }^{10}$ Marmur, J., J. Mol. Biol., 8, 208 (1961).

11 Colowick, S. R., and Kaplan, N. O., Methods in Enzymology, 8, 848 (Academic Press Inc., New York, 1957).

12 Wyatt, G. R., Biochem. J., 48, 581 (1951).

1s Marmur, J. P., and Doty, P., Nature, 183, 1427 (1959).

is Schildkraut, C. L., Marmur, J., and Doty, P., J. Mol. Biol., 4, 430 (1962). 